References:

[1] R Wakiya, et al. Hydroxychloroquine modulates elevated expression of S100 proteins in systemic lupus erythematosus. Lupus. 2019;28:826-833

Disclosure of Interests: None declared

DOI: 10.1136/annrheumdis-2020-eular.4149

\section{AB0392 1 THE EFFECT OF HYDROXYCHLOROQUINE ON THE RISK FACTORS FOR ATHEROSCLEROSIS DEVELOPMENT}

R. Wakiya ${ }^{1}$, K. Ueeda ${ }^{1}$, H. Shimada ${ }^{1}$, S. Nakashima ${ }^{1}$, M. Mahmoud Fahmy

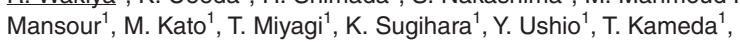
H. Dobashi'. ' Kagawa University, Division of Hematology, Rheumatology and Respiratory Medicine, Department of Internal Medicine, Kagawa, Japan

Background: Systemic lupus erythematosus(SLE) patients, especially patients with lupus nephritis have poor vascular endothelial function and increased cardiovascular(CV) mortality.

Meanwhile, several studies showed hydroxychloroquine(HCQ) has effect on reduction in lipids and thrombosis(1), but the mechanism is unclear.

Objectives: We examined effect of HCQ on adipocytokine expression in SLE patients.

Methods: 52 SLE patients with low disease activity started with HCQ were analyzed before and 3 months after HCQ treatment. 21 SLE patients has past history of lupus nephritis. Serum S100 proteins and adipocytokines were measured by ELISA, and serum inflammatory ctytokine levels were evaluated by Multiplex assay (TNF-a, IL-6, VEGF-A).

Results: Serum adiponectin level was increased significantly 3 months after $\mathrm{HCQ}$ treatment compared with those at baseline (mean change 1.35, Figure 1). SLE patients who achieved LLDAS had a greater increase than those who did not. Additionally, the changes of serum adiponectin levels were associated with those of TNF-a, IL-6, VEGF-A and S100A9 protein, which plays an important role of SLE pathogenesis.

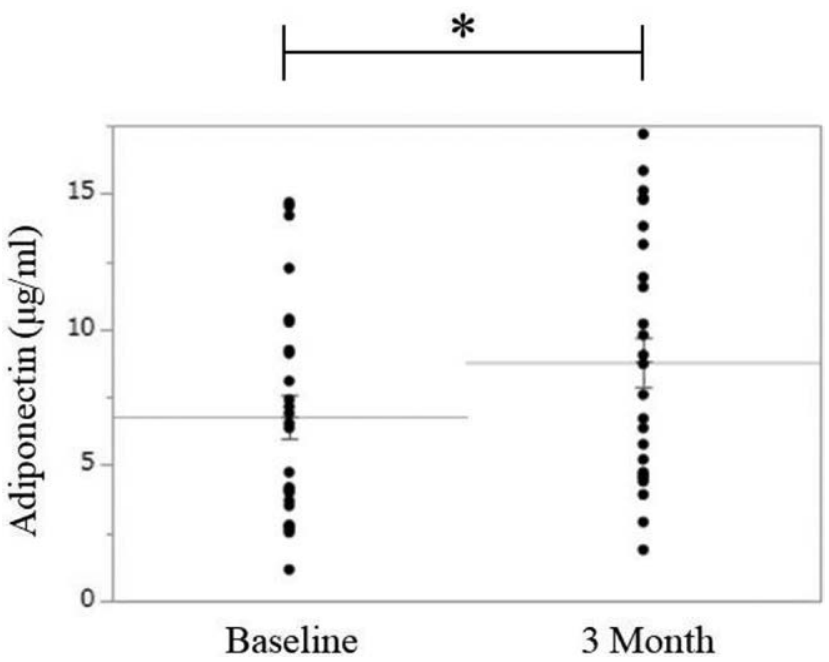

Figure 1. Serum adiponectin levels at baseline were compared with levels after 3 months of $\mathrm{HCQ}$ treatment. Serum adiponectin levels significantly decreasing during $\mathrm{HCQ}$ treatment in SLE patients. For statistical analyses * $p<0.0001, P$ value: Wilcoxon signed-rank test

Conclusion: A HCQ could reduce the risk factors for atherosclerosis along with control of SLE disease activity.

References:

[1] Wallace DJ, et al. Cholesterol-lowering effect of hydroxychloroquine in patients with rheumatic disease: reversal of deleterious effects of steroids on lipids. Am J Med. 1990; 89: 322-6.

Disclosure of Interests: None declared

DOI: 10.1136/annrheumdis-2020-eular.5449

\section{AB0393 \\ EFFICACY OF HYDROXYCHLOROQUINE FOR LUPUS NEPHRITIS IN MAINTENANCE PHASE}

M. Watanabe ${ }^{1}$, Y. Haji ${ }^{1}$, M. Kato ${ }^{1}$, T. Ito ${ }^{1}$, Y. Banno ${ }^{1}$, M. Okada ${ }^{2} .{ }^{1}$ Daido Hospital, Nagoya, Japan; '2St.Luke's International Hospital, Tokyo, Japan

Background: Hydroxychloroquine (HCQ) is an essential drug for systemic lupus erythematosus. But in Japan, chloroquine and HCQ remain unavailable until mid
2015 because of a series of lawsuits about its retinal toxicity in the 1970s. There is insufficient knowledge regarding renal protective effect of $\mathrm{HCQ}$.

Objectives: We aimed to investigate its efficacy of adding HCQ for Lupus nephritis (LN) as a maintenance-phase therapy.

Methods: We conducted an observational retrospective cohort study included patients with $\mathrm{LN}(\mathrm{n}=42)$ in maintenance-phase in Japan. We reviewed medical records of LN patients aged > 18 years who were initiated HCQ from May 2015 to May 2018. Maintenance phase was defined as stabilization in serum creatinine and urinary segment after induction therapy and who achieved complete or partial remission. The annual change of proteinuria was compared between patients on $\mathrm{HCQ}$ who have proteinuria $(>0.5 \mathrm{~g} / \mathrm{gCr}$ ) or not. Other outcome measures were disease flare, dose of steroids, renal and immunologic features.

Results: A total of 42 patients were analyzed and allocated to two groups based on their amount of daily urine protein level: $H C Q$ with proteinuria as group $A(>0.5 \mathrm{~g} / \mathrm{gCr}, \mathrm{n}=14)$ and $\mathrm{HCQ}$ without proteinuria as group $\mathrm{B}(\leqq 0.5 \mathrm{~g} /$ $\mathrm{gCr}, \mathrm{n}=28)$. Both groups were comparable, with mean (SD) age of $36.1(12.9)$ years and 37.5 (13.8), female $78.6 \%$ and $92.9 \%$ in each group, mean (SD) disease duration until $\mathrm{HCQ}$ of 3.5 (3.25) and 3.3 (2.9) years in group $A$ and group $\mathrm{B}$, with prednisolone dose at base line of 10.3 (7.1) $\mathrm{mg}$ and 7.9 (4.4) $\mathrm{mg}$, respectively. The mean (SD) proteinuria at base line was $1.38(1.11) \mathrm{g} /$ $\mathrm{gCr}$ in group $\mathrm{A}$ and $0.20(0.09) \mathrm{g} / \mathrm{gCr}$ in group $\mathrm{B}$ and after 12 months, proteinuria decreased in group $A(-1.34 \mathrm{~g} / \mathrm{gCr}$ in group $\mathrm{A}$ vs $+0.03 \mathrm{~g} / \mathrm{gCr}$ in group $B$; $\mathrm{p}<.001 ; 95 \% \mathrm{Cl}, 0.305-0.736)$. No relapse was experienced in group $A$ during the study period.

Conclusion: In patients with clinically stable LN but with proteinuria, hydroxychloroquine is a good therapeutic option for achievement of complete remission. Disclosure of Interests: None declared

DOI: 10.1136/annrheumdis-2020-eular.5378

\section{SLE, Sjögren's and APS - clinical aspects (other than treatment)}

AB0394

DOES HIGH DISEASE ACTIVITY IN SYSTEMIC LUPUS ERYTHEMATOSUS PATIENTS INCREASE THE RISK OF CANCER INCIDENCE?

A. Abdalla ${ }^{1}$, F. I. Abdelrahman ${ }^{2} .{ }^{1}$ Aswan University, Rheumatology and Rehabilitation, Aswan, Egypt; ${ }^{2}$ Zagazig University, Rheumatology and Rehabilitation, Zagazig, Egypt

Background: Cancer is known as one of the causes of morbidity and mortality in systemic lupus erythematosus (SLE) patients. It has been thought that SLE activity and stimulation of the immune system predisposes the risk of cancer (1)

Objectives: To investigate the correlation between SLE disease activity and the cancer incidence.

Methods: The study included a cohort of SLE patients, diagnosed according to the American College of Rheumatology classification criteria ${ }^{(2)}$ attending the Rheumatology department, Aswan University in the period from January 2018 to June 2019. We used a questionnaire to screen patients who were diagnosed with cancer. We collected demographic and laboratory data on all screened patients and their disease activity using the Systemic Lupus Erythematosus Disease Activity Index (SLEDAI) ${ }^{(3)}$. For the patients diagnosed with cancer, we recorded age of onset of SLE, age of diagnosis of cancer, type of cancer, treatment received, immunosuppressive regimen (dosage and duration) and cancer outcomes.

Results: The study included 117 patients (95 female, 22 male), mean age $(25.6 \pm 6.5)$ years with mean SLE duration $(7.3 \pm 6.3)$ years and mean SLE $\operatorname{DAl}(9 \pm 8.9) .76 \%$ had lupus nephritis, $62.2 \%$ had hematological abnormalities and $17.8 \%$ had neurophsycatric lupus. $91 \%$ were on corticosteroids (CCS), 33\% on mycophenolate mofetil (MMF), $43 \%$ on azathioprine, $14 \%$ on cyclosporin. $56.8 \%$ were either receiving or had received intravenous cyclophosphamide $(C Y C)$ with a mean cumulative dose $(7.5 \pm 4.7) \mathrm{gm}$. We found 18 (15.3\%) patients (13 female and 5 males) were diagnosed with cancer during the course of SLE with mean age at onset $(31 \pm 3.7)$, mean age at cancer diagnosis $(39.28 \pm 10.77)$, mean SLE duration(18.17 \pm 6.02$)$ and mean SLEDAI $(7.39 \pm 4.19)$. Most of SLE patients with cancer had lupus nephritis (89\%) and all cancer patients were on a median dose of CCS 10 (2.5-20) mg daily for median $10(4-24)$ years. $83.5 \%$ of them had received intravenous CYC prior to the development of cancer with mean total cumulative dose of $(6.7 \pm 4.6) \mathrm{gm}, 67 \%$ received MMF, $33 \%$ received cyclosporine and $50 \%$ received azathioprine. Types of cancer were as follow; $22.2 \% \mathrm{lym}-$ phoma, $16.7 \%$ cancer cervix, $16.7 \%$ cancer breast, $11.1 \%$ colorectal cancer, $11.1 \%$ squamous cell carcinoma, $5.6 \%$ leukemia, $5.6 \%$ bronchogenic carcinoma, $5.6 \%$ prostate cancer and $5.6 \%$ cancer thyroid. $66.7 \%$ of them 